\title{
Drug Utilization Pattern of Psychotropic Drugs Prescribed in the Psychiatric Department of a Tertiary Care Government Hospital, Rajasthan
}

\author{
Dr. Vandana Goyal ${ }^{1}$, Shifali Munjal ${ }^{2}$, Dr Rashmi Gupta ${ }^{3}$ \\ ${ }^{1}$ Professor, Department of Pharmacology, ${ }^{2}$ M.Sc. (Pharmacology ), $3^{\text {rd }}$ Year Student, ${ }^{3}$ Assistant Professor, \\ Department of community medicine JLN Medical College, Ajmer \\ Correspondence Author: \\ Dr Rashmi Gupta \\ Assistant Professor, Department of community medicine JLN Medical College, Ajmer \\ Email:drrashu53@rediffamil.com
}

\begin{abstract}
:
Introduction:

Psychiatric disorders form an important public health priority and major causes of morbidity. Drug utilization studies are a pre-requisite for the formulation of drug policies. This review identifies the problems that arise from drug usage in health care delivery system and highlights the current approaches to the rational use of drugs.

Objectives: to delineate the various drugs used in psychiatric disorders to find discrepancies, if any, between the actual and the ideal prescribing pattern of psychotropic drugs and to assess prevalence of various psychiatric illnesses .

Methodology: The retrospective non-interventional, study of 6 months duration ( $1^{\text {st }}$ Apr 2015 - 30 ${ }^{\text {th }}$ Sep 2015) was carried out by analyzing the copies of prescriptions of patients who had visited the O.P.D. of the Psychiatry Department of J.L.N. Medical College \& Associate groups of Hospitals Ajmer. After taking prior approval from Institutional Ethics Committee. we randomly collected 135 copies for each month, a total of 810 carbon copies were selected for study.

Result: Maximum number of patient's i.e. 395 (48.77\%) were in the age group of 21-40 years. Depression was the most common psychiatric illness (27.53\%) followed by substance abuse (18.15\%).Oral formulations accounts for $99.55 \%$ of total drugs prescribed and among oral formulations; tablet (88.43\%) was the most prescribed dosage form.

Most common classes of drugs prescribed for psychiatric indication were anxiolytics (26.95\%) followed by antidepressants (15.28\%), antipsychotics (14.43\%), anticonvulsants \& mood stabilizers (7.87\%).Among antianxiety drugs, Clonazepam (45.84\%), Escitalopram (29.79\%) was the antidepressant of choice overall Olanzapine was most commonly prescribed antipsychotics. Among typical agents, Chlorpromazine (9.23\%) was the most commonly prescribed antipsychotic. Sodium Valproate was the most commonly prescribed as anticonvulsant (46.25\%) \& mood stabilizer (49.38\%).
\end{abstract}

Keywords: Psychiatric disorders, Drug utilization

\section{Introduction}

Mental disorders are usually associated with significant distress in social, occupational, or other important activities. ${ }^{[1]}$ Major proportions of mental disorders come from low and middle income countries. ${ }^{[2]}$ Psychiatric disorders form an important public health priority and major causes of morbidity. ${ }^{[3]}$ Of the top ten health conditions contributing to the Disability Adjusted Life Years (DALYs), four are psychiatric disorders. ${ }^{[4]}$

For the treatment of psychiatric disorders, a wide array of psychotropic drugs is available. ${ }^{\text {[5] }}$ Psychiatrists are now very keen to use newer psychotropic medications in psychiatric practice which require vast study on their utilization and consequences on real life effectiveness and safety in actual clinical practice. ${ }^{[6]}$

Various factors like cost of drugs, local paradigms, etc. play a role in the selection of drug therapy and hence, affect the outcome. It is impossible to give suggestions for improving the attitude of physicians regarding the pattern of prescription without the knowledge of utilization pattern of drug.

Prescription order is an important transaction between the physician and patient. It brings into focus the diagnostic acumen and therapeutic proficiency of the physician with instruction for palliation or restoration of the patient's health. ${ }^{[7]}$ Now a days prescribing pattern is changing and it has become just an indication of medicine with some instructions of doses without considering its rationality. ${ }^{[8]}$ 
The rationality of prescribing pattern is of utmost importance because, bad prescribing habits includes misuse, overuse and underuse of medicines which can lead to unsafe treatment, exacerbation of the disease, health hazards, economic burden on the patients and wastage of resources. ${ }^{[9]}$

The principle aim of drug utilization research is to facilitate rational drug use in population. For the individual patient rational drug use implies the prescription of a well-documented drug in an optimal dose on the right indication, with the correct information and at an affordable price. Drug utilization research affords a baseline reference points about the effect of diverse interventions in prescribing the concerned drugs. ${ }^{[10]}$

Setting standards and assessing the quality of care through performance review should become part of everyday clinical practice. ${ }^{[11]}$ It oversees the observance of standards of medical treatment at all level of health care delivery system. It is concerned with the evaluation of medical care in retrospect through analysis of clinical records; to provide full benefits of medical knowledge effectively and rationally. ${ }^{\text {[12] }}$

It is a component of medical audit that does monitoring and evaluation of the drug prescribing patterns and suggests necessary modifications in prescribing practices to achieve rational therapeutic practice as well as cost effective health care. ${ }^{[13]}$

Bringing information on patterns of existing practice together with information on appropriate practice is an essential component of efforts to improve healthcare. This is possible only when each and every prescription in the hospital is audited by a prescription auditing team.

The process of prescription auditing in its broad sense include prescription monitoring, drug utilization studies, prescription pattern studies, study of prescription habits of doctors, adverse drug reaction monitoring, drug interaction monitoring, criteria based prescription auditing and many other activities. But the grass root activities include checking the prescription for drug name (brand name or generic), strength, formulation, dose, and route of administration, frequency, duration of treatment and drug allergies.

Drug utilization studies are a pre-requisite for the formulation of drug policies. This review identifies the problems that arise from drug usage in health care delivery system and highlights the current approaches to the rational use of drugs.

Data of utilization patterns of drugs at out-patient departments of tertiary care teaching hospitals and analysis of that data is a very beneficial measure to formulate guidelines for improving the pattern of prescriptions aligned to rationality \& effective outcome of the treatment with cost effectiveness. ${ }^{[14]}$

Measurement of drug use in health facilities not only describes drug use patterns and prescribing behavior but also helps in the identification of factors responsible for the practice of polypharmacy and the problems associated with it. ${ }^{[15]}$ Setting standards and assessing the quality of care through performance review should become part of everyday clinical practice. ${ }^{[16]}$ Keeping this in mind, present study was conducted to delineate the various drugs used in psychiatric disorders to find discrepancies, if any, between the actual and the ideal prescribing pattern of psychotropic drugs and to assess prevalence of various psychiatric illnesses .

\section{Material and Methods}

The retrospective non-interventional, study of 6 months duration ( $1^{\text {st }}$ Apr $2015-30^{\text {th }}$ Sep 2015) was carried out by analyzing the copies of prescriptions of patients who had visited the O.P.D. of the Psychiatry Department of J.L.N. Medical College \& Associate groups of Hospitals Ajmer.

After taking prior approval from Institutional Ethics Committee. we randomly collected 135 copies for each month, a total of 810 carbon copies were selected for study.To avoid undue bias of the physicians during prescribing to a patient, the principal copies were obtained from the office of the department of Psychiatry, J.L.N. Hospital, and Ajmer. Information on demographic profile, diagnosis and treatment were spread over different age groups. Study will include patients suffering from a psychiatric illness were included .In-patients, Diseases other then psychiatric illness and those cases in which diagnosis is not certain were excluded. The minimum sample size required in this study is 810 cases at $95 \%$ confidence interval and $10 \%$ allowable error to verify the expected proportion $30 \%$ depression which was the most common group of psychiatric conditions found in patients attending psychiatry outpatient department as per the seed article.

Data was analyzed disease-wise as per "International Classification of Disease" (I.C.D. - 10) as recommended by W.H.O. (1994) and drug-wise as per "Anatomic Therapeutic Chemical" (A.T.C.) classification recommended by W.H.O. (1993).

\section{Statistical Analyses}

Statistical analyses were done using computer software (SPSS Trial version 20 and primer). The qualitative data were expressed in proportion and percentages and the quantitative data expressed as mean and standard deviations. The difference in proportion was analyzed by using chi square test and significance level for tests were determined as $95 \%(\mathrm{P}<0.05)$. 


\section{Observation}

Total number of Prescriptions were studied 810, the M: F ratio was 1.86:1. Out of total 810 patients, $527(65.06 \%)$ were males whereas 283 (34.93\%) were females. No significant difference was observed according to age and sex. Cases were more in 21 - 40 years of age group in both the sex. (49\% in males and $48.41 \%$ in females) followed by 41 to 60 years of age group (35.5\% in males and $30.39 \%$ in females) least were in 0 to 20 years and $>80$ years of age group.

Out of 810 prescriptions analyzed, $59(7.28 \%)$ prescriptions were of patients below 20 years of age i.e. these patients were of Group 1. Maximum number of patients belongs to Group $2(48.77 \%)$. The next major number of patients was in age Group 3 i.e. $273(33.70 \%) .77(9.51 \%)$ patient belongs to age Group 4. Also there were $6(0.74 \%)$ patients who belongs to Group 5. 27.53\% prescriptions were of depression, $18.15 \%$ were of substance abuse, $15.19 \%$ were of bipolar disorders. $13.70 \%$ prescriptions were of schizophrenia, $8.15 \%$ were suffering from anxiety disorders. 5.56\% prescriptions were of seizure disorder. Rest $11.72 \%$ prescriptions were of other psychiatric illness. Other psychiatric illness includes insomnia, headache, migraine, mental retardation, dysthymia, obsessive compulsive disorder, alcohol withdrawl, nocturnal enuresis, dementia, parkinsonism, vertigo etc.

No significant difference was observed in Schizophrenia \& Other Psychoses Anxiety Disorders, Bipolar Disorders and Seizure Disorder according to sex. Depression was significantly more in females as compared to male (35.34\% Vs $23.34 \%)$ while Substance Abuse was significantly more in males as compared to female $(26.76 \%$ Vs $2.12 \%) \mathrm{P}<0.001 \mathrm{~S}$. The difference may be attributed to hormonal influence, childbirth effect $\&$ various psychosocial effects on women. Tablets $(88.43 \%)$ were the dosage form of choice by the prescribers, followed by the capsules (10.57\%). Injectables and liquid dosage forms were also prescribed in specific patients for better compliance.

Anxiolytics (26.95\%) and antidepressants (15.28\%) were the most frequent classes of drugs that were prescribed, followed by antipsychotics (14.43\%).Next most commonly prescribed agent were vitamins $13.92 \%$. Anticonvulsants and Mood Stabilizers (7.87\%) were also frequently prescribed. Medications for GIT (6.44\%) and analgesics $(7.12 \%)$ were prescribed least. Other drugs include anticholinergics, antihistaminics, antivertigo drugs, drugs for substance abuse, antibiotics, nootropics etc. which constitutes around $7.98 \%$ of all drugs prescribed.

Overall Prescribing Prevalence of Various Antianxiety Drugs: Out of total 3076 drugs prescribed, 829 were antianxiety drugs $(26.95 \%)$. Clonazepam $(45.84 \%)$ accounted for most commonly prescribed anxiolytic drug followed by Propranolol (21.71\%). Diazepam (10.86\%) and Chlordiazepoxide (10.74\%) were prescribed with nearly equal frequency among overall anxiolytic drugs. Lorazepam is least commonly prescribed antianxiety drug $(1.20 \%)$ during the study.

Antidepressant Drugs: Escitalopram is drug of choice (29.79\%) among all antidepressants, followed Fluoxetine $(24.47 \%)$, Sertraline $(21.91 \%)$, and Fluvoxamine $(0.64 \%)$. Imipramine and amitryptiline were prescribed with a prescribing frequency of $8.72 \%$ and $10.21 \%$. Among atypical antidepressants Mirtazapine and Bupropion were prescribed with a frequency of $3.83 \%$ and $0.43 \%$ respectively.

Prevalence of Antipsychotics: They accounted for $14.43 \%$ of total drugs during the study. Olanzapine was highly prescribed (7.18\%) antipsychotic drugs among all the antipsychotic drugs while study, followed by Risperidone $(4.55 \%)$ and Chlorpromazine $(1.33 \%)$. Rest antipsychotics with decreasing order of prescribing frequency are Haloperidol (0.69\%), Trifluoperazine (0.32\%), Flupenthixol (0.23\%), Aripiprazole $(0.1 \%)$ and least Clozapine $(0.1 \%)$.

Prevalence of Anticonvulsants and Mood Stabilizers: Accounted for 7.87\% of total drugs prescribed during the study. Sodium valproate was the anticonvulsant of choice prescribed during the study with a prescribing frequency of $46.25 \%$. The next most commonly prescribed agent was Phenytoin (25\%) followed by Phenobarbitone $(22.5 \%)$. Clobazam was also prescribed as an anticonvulsant $(6.25 \%)$ while during the study. Among mood stabilizers also Sodium Valproate (49.38\%) was prescribed in preference to Lithium Carbonate $(24.7 \%)$ and Carbamezapine $(25.92 \%)$ while during the study.

Prevalence of Vitamins, Minerals, Haematinics and Other Supplement Drugs: They constitute about 13.92 $\%$ of all drugs prescribed during the study. Vitamins accounted for $80.61 \%$ of total prescribed drugs within the group. $12.14 \%$ were iron a preparation, including both ferrous salts alone as well as ferrous salt with folic acid, within the group. Calcium preparations were $6.78 \%$ whereas UDCA accounts for $0.47 \%$ within the group. 
Drug Utilization Pattern of Psychotropic Drugs Prescribed in the Psychiatric Department of a...

Prevalence of Various GIT Drugs: Proton Pump Inhibitors were the choice among GIT drugs during the study (48.99 \%), followed by prokinetic drugs (20.71 \%). Proton Pump inhibitor (PPI's Combinations) and $\mathrm{H}_{2}$ Blockers $(8.08 \%)$ were also prescribed in a significant amount. Antimotility drugs, antispasmodics and laxatives were prescribed in $4.04 \%, 1.01 \%$, and $2.02 \%$ respectively.

Prevalence of Analgesics, Antipyretics and Muscle Relaxants: Opioid analgesic Tramadol is the most commonly prescribed drug (47.49\%). NSAIDs combinations (39.27\%) were preferred over NSAIDs alone $(8.22 \%)$ by the prescribers while during the study. Least prescribed drugs were antimigraine drug Flunarizine $2.28 \%$ and Muscle Relaxants Baclofen and Diclofenac Paracetamol Chloroxazone Combination 2.74\%.

Average number of drugs per prescription was 3.80 in our study. About $99 \%$ patients were exposed to 2 or more drugs. Most of the prescriptions contained 3 to 4 drugs per prescription. It was also found that 6 and above drugs per prescription $(5.80 \%)$ were also prescribed.

\section{Discussion}

This study was carried out to find out morbidity pattern of psychiatric diseases and prescribing trends of psychotropic drugs. The study of prescribing patterns seeks to monitor, evaluate and if necessary, suggest modifications in prescribing patterns so as to make medical care rational and cost effective.

The percentage of male patients on medical treatment for psychiatric illness was higher than female patients. Nearly similar results were also observed in a study carried out in outpatient department of psychiatry at tertiary care teaching hospital in Bastar region (68.18\% males v/s 31.81\% females). ${ }^{[61]}$ Another study conducted in schizophrenia patients in Nepal has also shown similar results. ${ }^{[24]}$ This may be due to the reason that males in the Indian Scenario had to deal with lots of burdens in their day to day life, be it the pressure of family sustenance, work pressure, social pressure, or burden of financial debts etc. Moreover the lifetime prevalence rate of substance abuse is much high in males as compared to females, thus leading to increased incidence of psychiatric illness in males.

Majority of patients belongs to age group 21-40 years (48.77\%). The results are in congruence to study conducted by Tabish A et al \& Mukherjee $S$ et al as maximum patients belongs to this age group in their respective studies as well. ${ }^{[61,68}\left[{ }^{[71]}\right.$ Increasing use of psychotropic drugs in this age group may be due to increased incidence of mental ill health, improved mental health literacy in general population, reduction in stigma associated with mental illness, increase in drug treatment option and due to more vigorous marketing of such agents. ${ }^{[18]}$

Major depression was the most common psychotic illness $(27.13 \%)$ present. It is also evident from several another studies that Major Depressive Disorder (MDD) is the most common psychotic illness. ${ }^{[\mathbf{1 9}, \mathbf{2 0 , 2 1 ]}}$ female patients with psychotic disorder presented with more severe mental deterioration in an advanced stage of the illness. This may be due to the lack of awareness by their family members and relatives or it may be due to higher depressive episodes in females due to increase hormonal influences.

Total of 3076 drugs were prescribed, among which oral formulations accounts for $99.55 \%$ \& parenteral preparations account for remaining $0.45 \%$. Our results closely matched with a study conducted by Dutta S, Beg MA et al. ${ }^{[22]}$ Mukherjee $S$ et al and Rode et al ${ }^{[20,21}$ This may be due to the fact that most of the patients attending psychiatry OPD belongs to adult age group and can take oral formulations safely and conveniently.

Anti-anxiety drugs were the most frequent class of drugs prescribed $(26.95 \%)$ followed by antidepressants $(15.28 \%)$ and antipsychotic drugs $(14.43 \%)$. Similar results were also observed in previously done studies in which anxiolytics were the most frequently prescribed class of drugs, antidepressants were second and antipsychotics were the third most common prescribed category. ${ }^{[\mathbf{2 0 , 2 1}]}$

Benzodiazepines are efficacious for a wide range of conditions such as anxiety, insomnia, tonic-clonic seizures and muscular spasms. In addition they were widely co-prescribed along-with antidepressants and antipsychotics thus justifying the fact that they were the most frequently prescribed drugs among all psychotropic medications.

Anticonvulsants \& mood stabilizers, which accounted to be part of $7.87 \%$ prescriptions. A similar result in relation to use of anticonvulsants \& mood stabilizers shown by study of Rode SB et al in which the prescribing frequency of these drugs was $7.6 \% .^{[21]}$

Benzodiazepines group was the most frequently prescribed group of antianxiety drugs. Further among all anti-anxiety drugs, Clonazepam was most commonly prescribed anti-anxiety agent (45.84\%) similar finding were observed in Grover S et al. ${ }^{[23]}$ and Rode SB et al ${ }^{[21]}$

Depression emerges out to be the most common ailment being treated during the study. In our study this finding is a beneficial aspect because current treatment guidelines recommend use of SSRIs as the first-line agents in patients of depression. ${ }^{[23]}$ SSRIs are generally free of sedative effects and safer at high doses. Better tolerability, combined with their mild adverse effects, accounts for their popularity as most widely prescribed 
antidepressants. ${ }^{[24]}$ These results were in accordance to Roopadevi HS et al ${ }^{[25]}$.They also found that Escitalopram was the most commonly prescribed

In about $47.03 \%$ of patients of depression, antidepressants were co-prescribed with antipsychotics. This is usually accepted as a treatment option for Bipolar Depression and in cases of Refractory depression. The effectiveness at low doses and a quick response is both very encouraging findings but their use should be justified keeping an eye on possible adverse effect profile of these agents.

Among tricyclic antidepressants, Imipramine and Amitryptiline were prescribed with a frequency of $8.72 \%$ and $10.21 \%$ respectively indicating lesser inclination of practitioners towards tricyclic antidepressants (TCAs).

In our study atypical antipsychotics were prescribed to $82.21 \%$ of patients. Atypical antipsychotics are now rated as first-line agents for treatment of psychoses because their low propensity to cause extra pyramidal side-effects (EPS), efficacy against refractory cases and better control against negative symptoms; better tolerance and low relapse rate and safer adverse effect profile.Atypical antipsychotics alleviate both positive and negative symptoms whereas typical antipsychotics can only treat negative symptoms. ${ }^{[26]}$ These were the probable reasons for more prescribing of atypical antipsychotics $(87.71 \%)$ to typical antipsychotics $(17.79 \%)$.

In our study among atypical antipsychotics, Olanzapine was the most commonly prescribed agent, Our findings closely matches with study of Grover $\mathrm{S}$ et al. ${ }^{[23,27]}$

The benefit of Olanzapine may be due to its greater efficacy, noticeable improvement of negative symptoms, higher response rate, better maintenance of treatment, and finally lower incidence of adverse effects ${ }^{[28]}$ Typical antipsychotic drugs accounts for $17.79 \%$ of total antipsychotic drug prescriptions indicating that they still play an important role in Schizophrenia and offer a valid alternative to atypical where atypical drugs are poorly tolerated or where typical are preferred by patients themselves. ${ }^{[29]}$

Chlorpromazine was the most commonly prescribed typical antipsychotic with a prescribing frequency of $9.23 \%$. The only injectable antipsychotic prescribed was Flupenthixol. Studies have shown that depot injections are useful in the management of schizophrenia in acute phases and also for maintenance treatment.

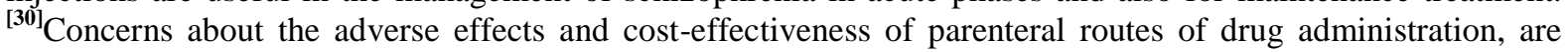
probably the reason for the low utilization of 'depot injection' formulation in the psychiatry OPD.

However some atypical antipsychotic also shows dose related EPS including tardive dyskinesia on long term use, weight gain and hyperprolactinemia. Essential difference between typical and atypical antipsychotic is the size of therapeutic index in relation to acute EPS.

Therefore, it has been suggested that therapeutic benefits and adverse effects of antipsychotic drugs should be separated by careful dosing.

Anticonvulsants were prescribed in $2.51 \%$ of prescriptions while mood stabilizers were prescribed in $5.36 \%$ of prescriptions. Their overall prevalence was $7.87 \%$ of total drugs prescribed during the study.

The overall prescribing frequency of mood stabilizers was found to be $5.36 \%$ in a study conducted by Rode SB et al which was in close approximation to our study. ${ }^{[21]}$ In a multicentric study conducted by Grover S et al ${ }^{[23]}$ and Avasthi A et al. ${ }^{[31]}$ the most common mood stabilizer prescribed was Valproate.

The overall prescribing frequency of Lithium was $1.3 \%$ while during the study. As similar to this the prescribing frequency of Lithium was $1.3 \%$ in a study conducted by Thakkar KB et al. ${ }^{[31]}$ Kessing et al ${ }^{[33]}$. But because of the low therapeutic index for Lithium $\left(\mathrm{Li}^{+}\right)$, periodic determination of serum concentrations is crucial ${ }^{[34]}$. The concern about its narrow therapeutic index and difficulty in obtaining drug levels of lithium, explains the low use of lithium in our center. In congruence to our study, Valproate was also the anticonvulsant of choice in a study conducted by Jena M $(57.30 \%){ }^{[27]}$

Vitamins, minerals and hematinics and other supplement comprised of $13.92 \%$ of all prescribed medications. Thiamine holds its major indication in patients of alcohol dependence as it prevents the development of Wernicke Korsakoff syndrome due to severe thiamine deficiency in chronic alcoholics. ${ }^{\text {[35] }}$

GIT drugs were included in $6.44 \%$ prescriptions of all patients attending the psychiatric OPD during the study. Out of which, Proton pump inhibitors (PPI's) comprised the most prescribed group with a prescribing frequency of $48.99 \%$. They are the most potent inhibitors of acid secretion available thus were the most frequently prescribed drug among GIT medications. ${ }^{[36]}$ Opioid analgesic Tramadol was the most commonly prescribed agent $(47.49 \%)$.

In this present study on an average $81.08 \%$ of prescriptions falls under the category of polypharmacy in patients of schizophrenia and depression as per the criterion of multiple psychotropic drugs prescribed to same patient. When studied according to criterion of multiple drugs prescribed for same indication, incidence of polypharmacy is less in depression as compared to schizophrenia.

In depression only $21.9 \%$ patients were prescribed more than one antidepressants whereas in schizophrenia the extent of multiple antipsychotics prescribed in single prescription is as high as $41.07 \%$.

Average number of drugs prescribed to a single patient was 3.80 which closely matches with studies conducted by Dutta $\mathrm{S}$ et al and Mukherjee $\mathrm{S}$ et al. ${ }^{[22,37]}$ 


\section{Conclusion}

All the drugs were prescribed by generic name and were from RMSC-EDL, this indicates the good prescription habit. Prescribing medicines by official names avoids the confusion and makes the drug therapy rational and cheaper.In our study this government policy was totally followed and all drugs were from state essential drug list. This is an extremely advantageous policy for common people as it ensures health compliance for all without implicating financial burden on patients. Therefore this policy should be followed in other states also.

\section{Bibliography}

[1] American Psychiatric Association. (2013). Diagnostic and statistical manual of mental disorders (5th ed.). Washington, DC.

[2] World Health Organization. Strengthening Mental Health Promotion. The World health report 2001 - Mental Health (Fact sheet no.220): New Understanding, New Hope., Geneva

[3] Math SB, Chandrashekar CR, Bhugra D. Psychiatric epidemiology in India. The Indian journal of Medical research 2007 Sep; 126(3): 183-92.

[4] Murthy R. Mental Health Programme in the 11th five year plan. The Indian Journal of Medical Research. 2007 Jun; 11: 707-12.

[5] Collins, Pamela Y; Patel, Vikram; Joestl, Sarah S et al. Scientific Advisory Board the Executive Committee."Grand challenges in global mental health". Nature 475(7354): 27-30.

[6] Piparva K. G, Parmar D. M, Singh A. P et al. Prospective cross-sectional analysis of psychotropic drugs in outpatient department of tertiary care hospital. Indian J Psychol Med 2011; 33(1): 54-58.

[7] Benet LZ. Principles of prescription order writing and patient's compliance instruction. In: Goodman AG, Rall TW, Nies AS Taylor P. (eds). Goodman and Gilman's The Pharmacological basis of therapeutics. $8^{\text {th }}$ ed. New York: Pergamon Press Inc. $1991 ; 1640$. (IJP 1998; 30:43-46).

[8] Gaud RS, Jain DK, Kashedikar SG et al. Critical evaluation of present prescribing pattern. Indian J Hosp Pharm 1989; $26: 70-72$.

[9] Hogerzeil HV. Promoting rational prescribing: an international perspective. Br J Clin Pharmacol 1995; 39: 1-6.

[10] Banerjee I, Roy B, Sathian B et al. Socio demographic profile and utilization pattern of antipsychotic drugs among schizophrenic inpatients: a cross sectional study from western region of Nepal. BMC Psychiatry 2013; 96: 1-2.

[11] Patterson HR, The problems of audit and research. J R Coll Gen Pract 1986; 36: 196.

[12] Gupta N, Sharma D, Garg SK et al. Auditing of prescriptions to study antimicrobials in a tertiary hospital. Indian J Pharmacol 1997; 29: 411-415.

[13] Farooq JA, Ajaz M, Pandita KK et al. Adrug utilization at SKIIMS tertiary care hospital: Clinical Pharmacology. JK-Practitioner 2013; 18(1-2): 35-40.

[14] Lunde PKM, Baksaas L. The methodology of drug utilization studies; WHO Reg Pub Eur Series 1979; 17.1

[15] WHO. Action programme for Essential drugs. How to investigate drug use in health facilities. WHO, 1993.

[16] Patterson HR, The problems of audit and research. J R Coll Gen Pract 1986; 36: 196

[17] Jorm A, Christensen H, Griffiths K. Changes in depression awareness and attitudes in Australia: the impact of beyondblue: the national depression initiative. Australian and New Zealand Journal of Psychiatry, 2006; 40: 42-46.

[18] Jorm A, Christensen H, Griffiths K. Changes in depression awareness and attitudes in Australia: the impact of beyondblue: the national depression initiative. Australian and New Zealand Journal of Psychiatry, 2006; 40: 42-46.

[19] Tabish A, Sharma S, Sajid A et al. Drug utilisation research in psychiatry outdoor in tertiary care hospital, Bastar region. IJPR 2015; 5 (4).

[20] Dutta S, Kaul V, Beg MA et al. A psychotropic drug use study among depression patients attending private psychiatric practitioners of Dehradun, Uttarakhand. Int J Med Sci Public Health. 2015; 4(5): 634-638

[21] Rode SB, Ajagallay RK, Salankar HV et al. A study of drug prescribing pattern in psychiatry out-patient department of a tertiary care teaching hospital. Int J Basic Clin Pharmacol 2014; 3(3): 517-522.

[22] Dutta S, Beg MA, Sindhu S et al. Role of pharmaco-epidemiology in psychopharmacology: a study in psychiatric out-patient department of a tertiary care teaching hospital at Dehradun, Uttarakhand. Int J Basic Clin Pharmacol. 2014; 3(4): 637-643.

[23] Grover S, Avasthi A, Sinha V et al. Indian Psychiatric Society multicentric study: Prescription patterns of psychotropics in India. Indian Journal of Psychiatry 2014 Jul-Sep; 56(3).

[24] Potter WZ, Hollester LE. Antidepression Agents. In: Katzung BG, editor. Basic and Clinical Pharmacology. 10 $0^{\text {th }}$ edition. Boston: McGraw-Hill. 2007; 475-88.

[25] Roopadevi HS, Ramesh KN, Nagabhushan H. Pattern of psychotropic prescription in a tertiary care teaching hospital: A critical analysis. Asian Journal of Pharmaceutical \& Clinical Research 2015; 8(5).

[26] Serretti A, De Ronchi D, Lorenzi C et al: New antipsychotics and schizophrenia: a review on efficacy and side effects. Curr Med Chem 2004 Feb, 11(3): 343-58.

[27] Jena M, Mishra S, Mishra SN et al. Psychotropic drugs prescription pattern in outdoor of tertiary care hospital. Int J Pharm 2014; 4(4): 204-208.

[28] Tran PV, Hamilton SH, Kuntz AJ et al. "Double-blind comparison of olanzapine versus risperidone in the treatment of schizophrenia and other psychotic disorders". Journal of Clinical Psychopharmacology, 1997; 17(5): 407-418.

[29] Oosthuizen P, Emsley RA, Turner J et al. Determining the optimal use of haloperidol in first episode psychosis; J Psychopharmacol 2001; 15: 25 .

[30] Avasthi A, Aggarwal M, Grover S et al. Research on antipsychotics in India. Indian Journal of Psychiatry Jan 2010; 52(1): 317-40.

[31] Avasthi A, Grover S, Kulhara P et al. An audit of first prescription of new patients attending a psychiatry walk-in-clinic in north India. Indian Journal of Pharmacology, 2012 May-June; 44(3): 319-325.

[32] Thakkar KB, Jain MM, Billa G et al. Drug utilization Study - Psychotropic Drugs Journal of Clinical and Diagnostic Research. 2013 Dec; 7(12): 2759-2766.

[33] Avasthi A, Aggarwal M, Grover S et al. Research on antipsychotics in India. Indian Journal of Psychiatry Jan 2010; 52(1): 317-40.

[34] Brunton L, Parker K, editors.Pharmacotherapy of Psychosis and Mania.Goodman \& Gilman's The Pharmacological Basis of Therapeutics. 12th ed. USA: McGraw-Hill; 2010.

[35] Sechi G, Serra A. Wernicke's encephalopathy: new clinical settings and recent advances in diagnosis and management. Lancet Neurology 2007; 6: 442-55.

[36] Sachs G, Shin J M, Howden C W. "Review article: The clinical pharmacology of proton pump inhibitors". Alimentary Pharmacology and Therapeutics 2006; 23: 2-8. 
Drug Utilization Pattern of Psychotropic Drugs Prescribed in the Psychiatric Department of a...

[37] Mukherjee S, Sen S, Chatterjee SS et al. Prescribing pattern of psychotropic medications in psychiatry outpatients at a tertiary care teaching hospital in India: A prospective cross-sectional study. International Journal of Hospital Research 2014, 3(3): 113-122

Table No1: Characteristics of the Auditing Prescriptions

\begin{tabular}{|c|c|c|c|c|c|c|}
\hline & \multicolumn{6}{|c|}{ Number of Prescriptions } \\
\hline Age Group & \multicolumn{2}{|c|}{$\begin{array}{l}\text { Male } \\
(527(65.06 \%)\end{array}$} & \multicolumn{2}{|c|}{$\begin{array}{l}\text { Female } \\
(283(34.93 \%)\end{array}$} & \multicolumn{2}{|c|}{ Total(810) } \\
\hline (years) & No. & $\%$ & No. & $\%$ & No. & $\%$ \\
\hline $0-20$ & 31 & 5.88 & 28 & 9.89 & 59 & 7.28 \\
\hline $21-40$ & 258 & 49 & 137 & 48.41 & 395 & 48.77 \\
\hline 41-60 & 187 & 35.5 & 86 & 30.39 & 273 & 33.7 \\
\hline $61-80$ & 46 & 8.73 & 31 & 10.95 & 77 & 9.51 \\
\hline$>80$ years & 5 & 0.95 & 1 & 0.35 & 6 & 0.74 \\
\hline \multicolumn{7}{|c|}{ Chi-square $=7.338$ with 4 degrees of freedom; $\mathrm{P}=0.119 \mathrm{NS}$} \\
\hline \multirow{2}{*}{$\begin{array}{l}\text { Schizophrenia \& } \\
\text { Other Psychoses }\end{array}$} & & & & & & \\
\hline & 63 & 11.95 & 48 & 16.96 & 111 & $0.062 \mathrm{NS}$ \\
\hline \multirow[t]{2}{*}{ Anxiety Disorders } & & & & & & \\
\hline & 44 & 8.34 & 22 & 7.77 & 66 & $0.88 \mathrm{NS}$ \\
\hline \multirow[t]{2}{*}{ Bipolar Disorders } & & & & & & \\
\hline & 73 & 15.47 & 50 & 17.67 & 123 & $0.18 \mathrm{NS}$ \\
\hline Depression & 123 & 23.34 & 100 & 35.34 & 223 & $<0.001 \mathrm{~S}$ \\
\hline \multirow[t]{2}{*}{ Substance Abuse } & & & & & & \\
\hline & 141 & 26.76 & 6 & 2.12 & 147 & $<0.001 \mathrm{~S}$ \\
\hline \multirow[t]{2}{*}{ Seizure Disorders } & & & & & & \\
\hline & 28 & 5.31 & 17 & 6.01 & 45 & $0.80 \mathrm{NS}$ \\
\hline \multirow{2}{*}{$\begin{array}{l}\text { Other Psychiatric } \\
\text { Illness }\end{array}$} & & & & & & \\
\hline & 55 & 10.44 & 40 & 14.13 & 95 & $0.14 \mathrm{NS}$ \\
\hline
\end{tabular}

Figure No:1 Psychiatric Disorders



Figure No:2 Overall Prescribed Medicines

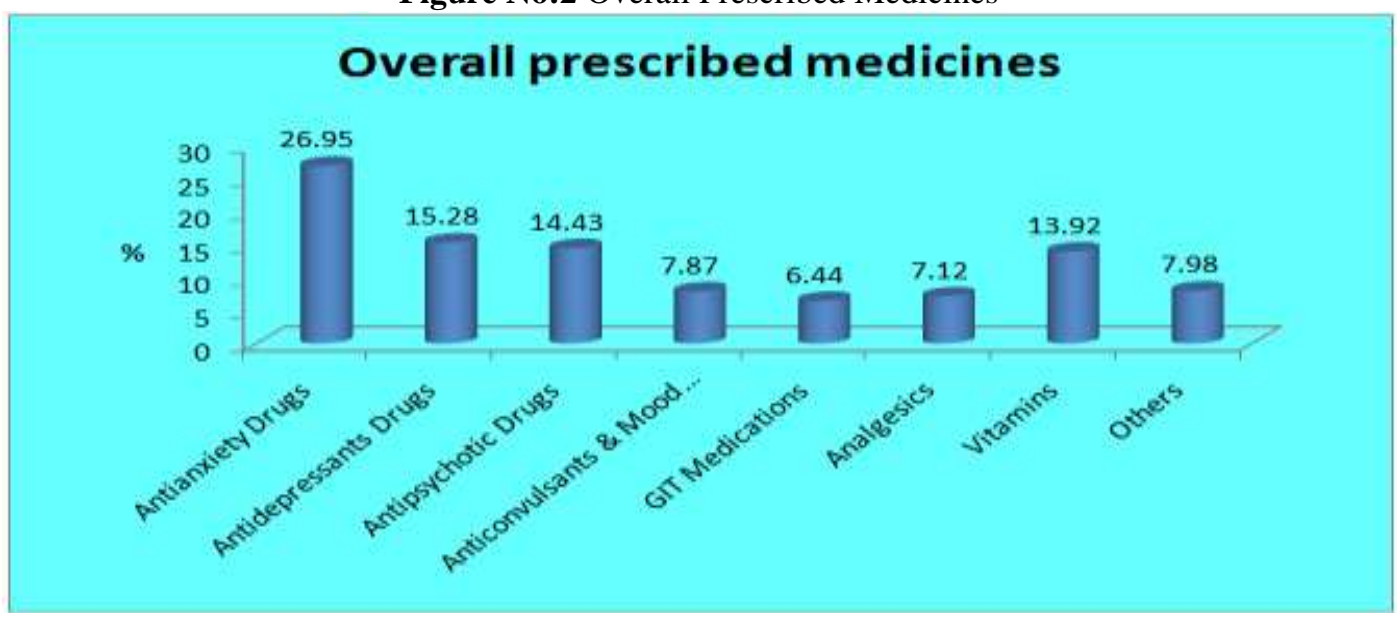

Table No: 2Various Commonly Prescribed Drugs and Their Frequency 
Drug Utilization Pattern of Psychotropic Drugs Prescribed in the Psychiatric Department of a...

\begin{tabular}{|c|c|c|c|}
\hline \multirow[b]{2}{*}{ Anxiolytics(N=829) } & \multirow[b]{2}{*}{ Number Of Drugs } & \multicolumn{2}{|c|}{ Prescribing Frequency (\%) } \\
\hline & & Among Drug & As a Whole( out of 3079) \\
\hline Alprazolam & 80 & 9.65 & 2.6 \\
\hline Lorazepam & 10 & 1.2 & 0.33 \\
\hline Clonazepam & 380 & 45.84 & 12.35 \\
\hline Diazepam & 90 & 10.86 & 2.93 \\
\hline Chlordiazepoxide & 89 & 10.74 & 2.9 \\
\hline Propranolol & 180 & 21.71 & 5.85 \\
\hline Total & 829 & 100 & 26.95 \\
\hline \multicolumn{4}{|l|}{ Antidepressant $(\mathrm{N}=470)$} \\
\hline Escitalopram & 140 & 29.79 & 4.55 \\
\hline Sertraline & 103 & 21.91 & 3.35 \\
\hline Fluoxetine & 115 & 24.47 & 3.74 \\
\hline Fluvoxamine & 3 & 0.64 & 0.1 \\
\hline Imipramine & 41 & 8.72 & 1.33 \\
\hline Amitryptiline & 48 & 10.21 & 1.56 \\
\hline Mirtazapine & 18 & 3.83 & 0.59 \\
\hline Bupropion & 2 & 0.43 & 0.06 \\
\hline Total & 470 & 100 & 15.28 \\
\hline \multicolumn{4}{|l|}{ Antipsychotic(N=444) } \\
\hline Risperidone & 140 & 31.53 & 4.55 \\
\hline Olanzapine & 221 & 49.78 & 7.18 \\
\hline Clozapine & 1 & 0.23 & 0.03 \\
\hline Aripirazole & 3 & 0.67 & 0.1 \\
\hline Flupenthixol & 7 & 1.58 & 0.23 \\
\hline Chlorpromazine & 41 & 9.23 & 1.33 \\
\hline Trifluoperazine & 10 & 2.25 & 0.32 \\
\hline Haloperidol & 21 & 4.73 & 0.69 \\
\hline Total & 444 & 100 & 14.43 \\
\hline \multicolumn{4}{|l|}{ Anticonvulsants(N-80) } \\
\hline Phenytoin Sodium & 20 & 25 & 0.65 \\
\hline Phenobarbitone Sodium & 18 & 22.5 & 0.59 \\
\hline Sodium Valproate & 37 & 46.25 & 1.2 \\
\hline Clobazam & 5 & 6.25 & 0.07 \\
\hline \multicolumn{4}{|l|}{ Mood Stabilizers(N=162) } \\
\hline Lithium Carbonate & 40 & 24.7 & 1.3 \\
\hline Carbamezapine & 42 & 25.92 & 1.36 \\
\hline Sodium Valproate & 80 & 49.38 & 2.7 \\
\hline Total & 162 & 100 & 5.36 \\
\hline
\end{tabular}

Table no: 3 Number of Drug(s) Per Prescription

\begin{tabular}{|l|l|l|l|}
\hline \multicolumn{2}{|l|}{ Prescription } & \\
\hline $\begin{array}{l}\text { Number of drug(s) } \\
\text { per prescription }\end{array}$ & Number & Percentage & Total Number of Drugs \\
\hline $\mathbf{1}$ & 8 & 0.99 & 8 \\
\hline $\mathbf{2}$ & 61 & 7.53 & 122 \\
\hline $\mathbf{3}$ & 254 & 31.36 & 762 \\
\hline $\mathbf{4}$ & 310 & 38.27 & 1240 \\
\hline $\mathbf{5}$ & 130 & 16.05 & 650 \\
\hline $\mathbf{6}$ & 35 & 4.32 & 210 \\
\hline $\mathbf{7}$ & 12 & 1.48 & 84 \\
\hline Total & $\mathbf{8 1 0}$ & $\mathbf{1 0 0}$ & $\mathbf{3 0 7 6}$ \\
\hline Average Number of Drugs Per Prescription=3.80 \\
\hline
\end{tabular}

